Article

\title{
Interfacial Microstructure Analysis of AZ31 Magnesium Alloy during Plastic Deformation Bonding
}

\author{
Limei Ren ${ }^{1,2}$, Bei Li ${ }^{1,2}$, Zhaoxiang Chen ${ }^{2,3, *}$, Shan Gao ${ }^{1,2}$, Yongqiang Quan ${ }^{1,2}$ and Lihe Qian ${ }^{4}$ \\ 1 Key Laboratory of Advanced Forging \& Stamping Technology and Science (Yanshan University), Ministry of \\ Education of China, Qinhuangdao 066004, China; lmren@ysu.edu.cn (L.R.); 15690051975@163.com (B.L.); \\ gaoshan@stumail.ysu.edu.cn (S.G.); 17625117290@163.com (Y.Q.) \\ 2 School of Mechanical Engineering, Yanshan University, Qinhuangdao 066004, China \\ 3 Key Laboratory of Self-Lubricating Spherical Plain Bearing Technology of Hebei Province, \\ Yanshan University, Qinhuangdao 066004, China \\ 4 State Key Laboratory of Metastable Materials Science and Technology, Yanshan University, \\ Qinhuangdao 066004, China; lhqian@ysu.edu.cn \\ * Correspondence: zxchen@ysu.edu.cn; Tel.: +86-335-806-8374
}

Citation: Ren, L.; Li, B.; Chen, Z.; Gao, S.; Quan, Y.; Qian, L. Interfacial Microstructure Analysis of AZ31 Magnesium Alloy during Plastic Deformation Bonding. Processes 2021, 9, 1857. https://doi.org/10.3390/ pr9101857

Academic Editor: Yuan Yuan

Received: 17 September 2021

Accepted: 12 October 2021

Published: 19 October 2021

Publisher's Note: MDPI stays neutral with regard to jurisdictional claims in published maps and institutional affiliations.

Copyright: (c) 2021 by the authors. Licensee MDPI, Basel, Switzerland. This article is an open access article distributed under the terms and conditions of the Creative Commons Attribution (CC BY) license (https:// creativecommons.org/licenses/by/ $4.0 /)$.

\begin{abstract}
In this study, a plastic deformation process consisting of hot compression at $350{ }^{\circ} \mathrm{C}$ and heat treatment at $400{ }^{\circ} \mathrm{C}$ was performed to bond AZ31 magnesium alloy. Microstructural evolution around the bonding interface was systematically characterized to investigate the bonding process and clarify the bonding mechanism. When the plastic deformation strain reached 0.6 , the bonding zone was full of fine dynamic recrystallized grains and the initial interface was eliminated. The post-heating treatments were conducted to achieve a sound interface bonding. The tensile tests and the corresponding fracture morphologies analysis indicated that the optimum holding time of heat treatment was $8 \mathrm{~h}$. The interfacial bonding strength of the specimens holding for $8 \mathrm{~h}$ reached 164.7 MPa, an enhancement of about 9\% compared with that of the specimens holding for $1 \mathrm{~h}$. The microstructure analysis indicated that the bonding quality was affected by migration of the interfacial grain boundary (GB), the development of recrystallized grains and the evolution of interfacial oxides around the bonding area.
\end{abstract}

Keywords: interfacial microstructure; plastic deformation; bonding; AZ31 magnesium alloy; grain boundary

\section{Introduction}

Magnesium and its alloys have attracted considerable attention in the automotive and aerospace industries due to their high specific strength, low density, good thermal conductivity, and excellent damping performance [1,2]. The magnesium alloy components used in the above industrial fields usually have complex structures and need to meet mechanical requirements under certain service conditions. However, the direct forming of magnesium alloy components with complex structure is very difficult and comes with high costs [3,4]. Though a welding process is normally applied when joining metal in many structural components, the mechanical properties of welded parts are relatively poor. In comparison with the traditional welding process, solid-state bonding is a promising method to realize metallurgical metal bonding without the need to melt materials [5].

Based on the solid state bonding process, many advanced techniques have been successfully applied in the joining of metal, such as friction stir welding (FSW) [6], accumulative roll bonding (ARB) [7], and diffusion bonding (DB) [8]. Although these techniques rely on different mechanisms, the critical process to achieve a good bonding quality is the elimination of the initial bonding line at the interface. Furthermore, the mechanical properties of bonded joints rely on the quality of the bonding interface, which is mainly influenced by the bonding parameters [9]. Solid state bonding is usually conducted at 
a temperature below the melting point of materials to be bonded, and can be applied with either small or large deformation. Zhang et al. [10] reported that TC4 titanium alloy was diffusion bonded under small deformation $(<0.5 \%)$, and revealed a main bonding mechanism of volume and surface diffusion. A study on martensitic stainless steel joints proved that a slight deformation of the contact surface coupled with long-term diffusion bonding induced interfacial grain boundary migration, leading to satisfactory bonding [11]. On the other hand, solid state bonding with large deformation was also investigated for joining various metallic materials. Zhang et al. [12] demonstrated the microstructural evolution of copper bonded at a range of deformation strain up to 0.7 . It was found that the hardness values in the bonding area increased with increasing strain. Xie et al. [13] investigated the solid state bonding of 316LN stainless steel and showed that the interface bonding process was promoted through heat treatment. Obviously, the mechanical properties of solid state bonding joints are dependent on the interfacial microstructure [14]. It is well known that severe plastic deformation results in dynamic recrystallization (DRX) of microstructures [15]. For this reason, many studies have investigated the development of dynamic recrystallized (DRXed) grains during solid state bonding processes with large deformation $[16,17]$. Unlike in bonding with very small deformation, DRXed grains play an important role in bonding with large deformation. The former essentially belongs to the class of diffusion bonding, while the latter can be defined as plastic deformation bonding (PDB). To date, research on the joining of copper, steel and titanium alloys by applying PDB has been reported $[12,13]$. It is considered to be a promising joining technique for achieving reliable metallurgical bonding for producing complex structural components. However, the feasibility and the bonding mechanism behind the PDB of AZ31 magnesium alloy are not yet clear, which may severely restrict its range application. Furthermore, the interactions among the bonding parameters, the interfacial microstructure and the mechanical properties of AZ31 magnesium alloy joints are far from being understood.

In the present study, hot compression bonding under different strains, followed by heat treatment, was carried out on AZ31 magnesium alloy. This paper mainly focuses on the effects of the plastic deformation and holding time on the interfacial GB migration during the bonding process. Special attention was paid to discussing how evolution of the interfacial microstructure affected the bonding quality. The tensile properties and fracture morphologies were analyzed as well to clarify the influence of process parameters on bonding strength. The results could provide knowledge and guidance for applying solid-state bonding in order to manufacture magnesium alloy components with more complex structures.

\section{Materials and Methods}

AZ31 magnesium alloy was used as base material, with a chemical composition (in wt. \%) of $3.04 \mathrm{Al}, 0.99 \mathrm{Zn}, 0.29 \mathrm{Mn}, 0.01 \mathrm{Fe}, 0.02 \mathrm{Si}, 0.01 \mathrm{Cu}$, and the balance $\mathrm{Mg}$. Figure 1 illustrates the experimental configuration. Two kinds of specimens (the dog-bone-shaped specimen and the stepped cylindrical specimen in Figure 1a) were machined from the base material and used for hot compression. The bonding surfaces of the stepped cylindrical specimens were polished with SiC paper and cleaned with absolute ethanol to remove surface contamination, then dried by flow of warm air. Hot compression experiments were carried out with a Gleeble-3800 thermo-mechanical simulator with a temperature of $350{ }^{\circ} \mathrm{C}$, strain rate of $0.1 \mathrm{~s}^{-1}$, and strain $(\varepsilon)$ of $0.1-0.6$. Figure $1 \mathrm{~b}$ shows the hot compression and heat treatment process. Specimens were heated at a rate of $5{ }^{\circ} \mathrm{C} / \mathrm{s}$ to the deformation temperature of $350{ }^{\circ} \mathrm{C}$ and then maintained at this temperature for $60 \mathrm{~s}$ to eliminate the temperature gradient. The specimens were then compressed until the selected engineering strain was reached, and the pressure and temperature were maintained for $180 \mathrm{~s}$. The compressed specimens were divided into different groups and sealed in vacuum tubes. Thereafter, the sealed specimens were heated in a furnace up to $400^{\circ} \mathrm{C}$ and held for $1 \mathrm{~h}, 2 \mathrm{~h}, 4 \mathrm{~h}, 8 \mathrm{~h}$ and $12 \mathrm{~h}$, respectively. 
(a)

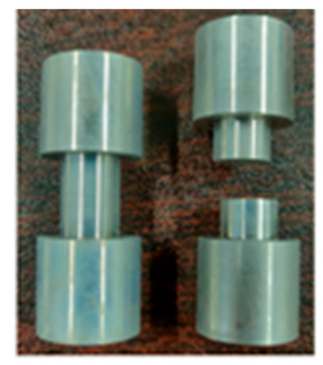

(c)

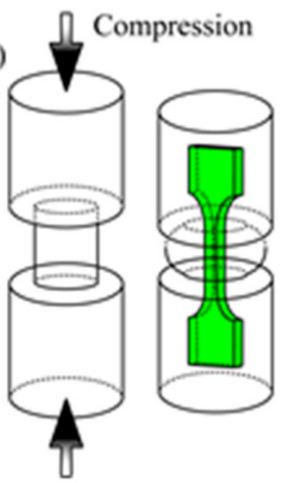

(b)

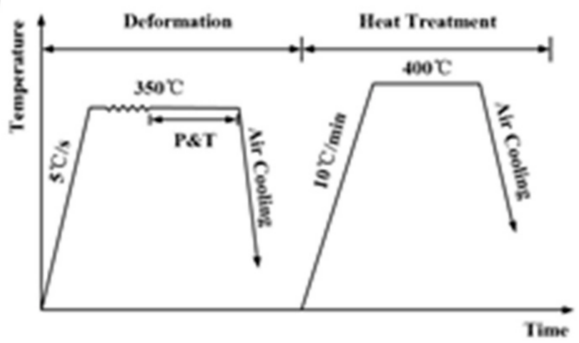

(d)

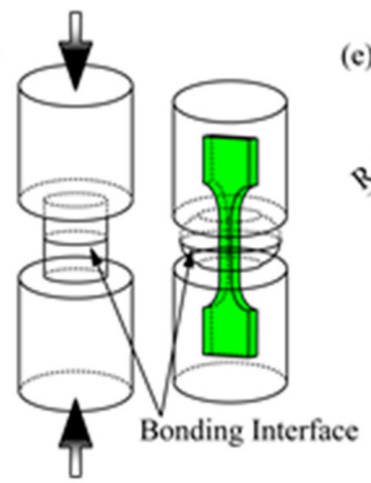

(e)

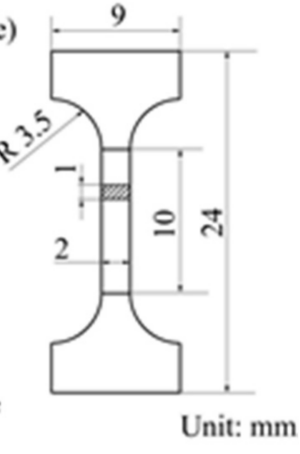

Figure 1. Illustration for the experiments: (a) Photograph of the specimens prepared for hot compression; (b) Hot compression and post-heating treatment process; (c) Schematic of tensile specimens cut from the base material; (d) Schematic of tensile specimens cut from the bonded specimen; (e) Geometry and size of the tensile specimen.

In order to observe the interfacial microstructure, the specimens were cut along the central cross section parallel to the compression direction. The specimens for microstructure observation were prepared via standard mechanical grinding and polishing procedures. The polished specimens were then etched with a solution of $5 \mathrm{~g}$ picric acid, $5 \mathrm{~mL}$ acetic acid, $100 \mathrm{~mL}$ ethanol and $20 \mathrm{~mL}$ distilled water. The interfacial morphologies were characterized by using an optical microscope (OM) and a ZEISS SIGMA 500 scanning electron microscope (SEM) equipped with energy dispersive X-ray spectroscopy (EDS). Tensile tests were performed at room temperature using an INSPEKT $100 \mathrm{kN}$ machine. The tensile specimens with thickness of $1 \mathrm{~mm}$ were machined from the as-compressed and heat-treated specimens of base materials and bonded specimens along the compression direction (Figure 1c,d). The geometry of the uniaxial tensile specimen is shown in Figure 1e.

\section{Results}

\subsection{Microstructure around the Bonding Interface Under Different Strains}

Figure 2 presents the microstructure evolution around the bonding interface under different deformation strains (0.1-0.6). It can be seen that dynamic recrystallized (DRXed) grains became distributed around the interface, and the bonding interface was gradually eliminated with increasing deformation strain. In Figure 2a, there are a few fine DRXed grains evolved around the interface, and the straight bonding line of the interface is evident. When the strain was increased to 0.2 , the region of DRXed grains around the interface increased with further deformation, as shown in Figure $2 b$. These DRXed grain boundaries are aligned along the bonding interface. Despite the increasing number of DRXed grains, the bonding interface is still easily spotted. These results imply that the specimens could not be successfully bonded at this strain level. 

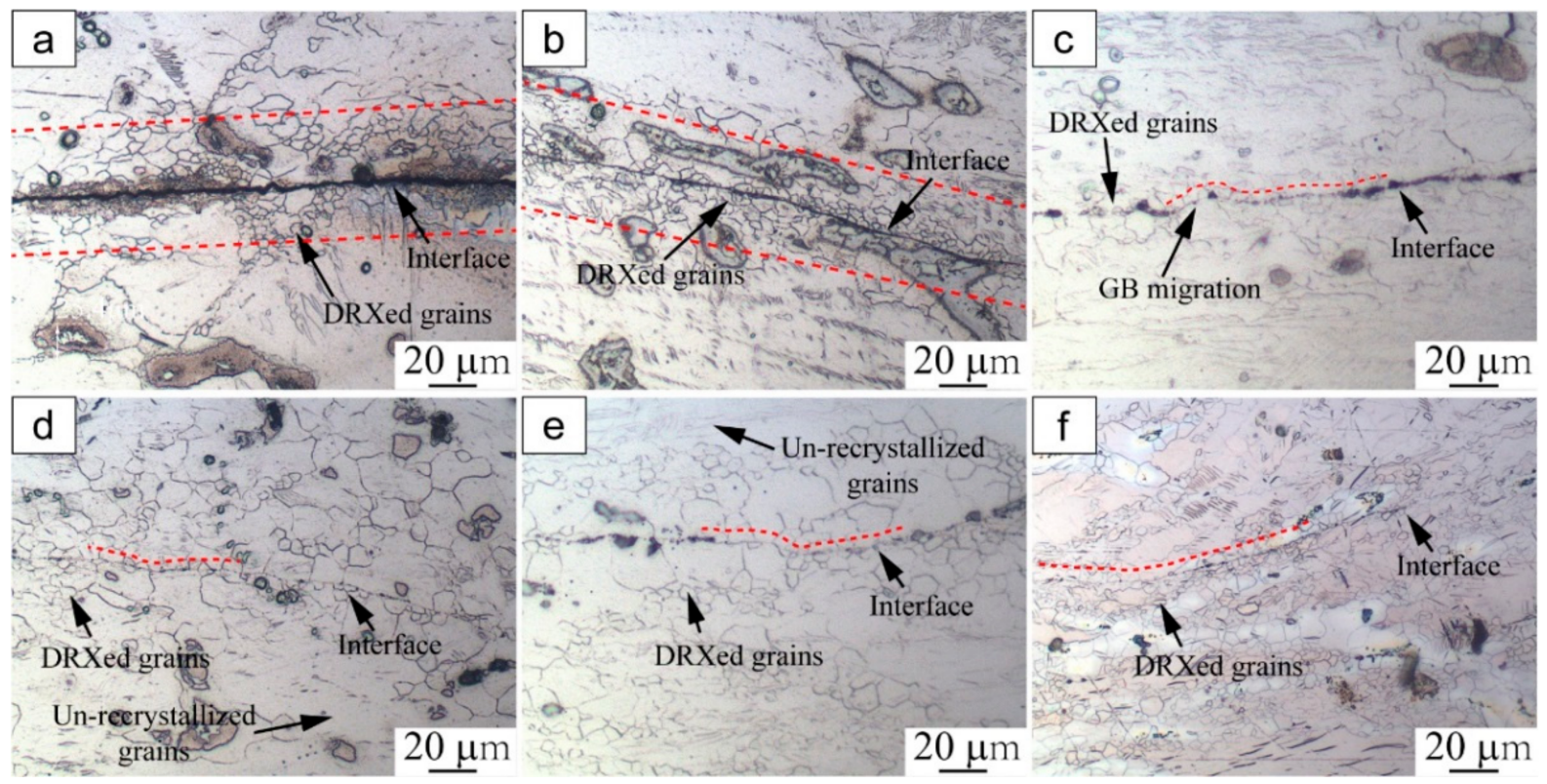

Figure 2. Microstructure around the bonding interface of specimens compressed at $350{ }^{\circ} \mathrm{C}$ under different strains: (a) 0.1 , (b) 0.2, (c) 0.3, (d) 0.4, (e) 0.5 , (f) 0.6 .

In Figure 2c, fine DRXed grains appear to be gradually coarsened and the bonding interface has merged into the matrix of the base metal at a strain of 0.3. The GB bonding first occurred at the interface, and part of the bonding interface became non-obvious. When the strain was further increased to 0.4 , the bonding interface was distributed with fine DRXed grains and coarse un-recrystallized grains. As a result of the development of these fine DRXed grains, the compressed specimens bonded gradually (Figure 2d). When the strain was increased to 0.5 and 0.6 , the bonding zone was full of fine DRXed grains and the initial bonding interface could hardly be recognized (Figure 2e,f).

As mentioned above, during the initial stage of hot compression, DRXed grains were generated around the interface and the interfacial bonding line was essentially flat. The formation and growth of fine DRXed grains accompanied the interface bonding process as the strain increased. Plastic deformation is known to promote the flow of interfacial material to overcome the surface roughness and guarantee sufficient contact of the adjacent plates $[12,18]$. The results are consistent with the reported findings, indicating that increasing plastic deformation promoted the bonding of AZ31 magnesium alloy. Moreover, it was noted that the bonding interface became obviously serrated under a strain of 0.3 . These phenomena were induced by GB bulging, and the serrated areas were proven to be possible sites for subsequent DRXed nucleation $[19,20]$. According to the microstructure observations, the initial DRXed grains were generated on the sites of GB bulging at low levels (0.1-0.3). This indicates that discontinuous dynamic recrystallization was the main nucleation mechanism for the specimens at low strain levels. As the deformation strain increased, the initial bonding line was eliminated due to the continuous migration of interfacial grain boundaries.

Hence, the mechanism of strain-induced GB migration can be used to explain interface grain bulging and evolution in the bonding area. In light of this mechanism, the strain-induced GB migration is driven by the stored energy difference associated with the difference in the dislocation contents between the opposite sides of the grain boundary [6]. Owing to the discrepancy in potential activation of different slip systems and the local inhomogeneity of plastic deformation, different dislocation densities develop inside the adjacent grains. Consequently, GB bulging is driven by the energy difference between adjacent grains, and is an indication of strain-induced grain boundary migration [12]. In short, the fresh bonding interface first joins to atomically form a grain boundary; the driving force for the GB migration is then achieved by strain-induced dislocation accumulation. 
Evolution of the interfacial microstructure indicates that the bonding process is closely related to the development of fine DRXed grains under high strain level (0.4-0.6). Furthermore, the volume fraction and size of the DRXed grains increases with increased plastic deformation strain. The larger deformation offers more energy for interface bonding and atom diffusion, leading to better bonding quality $[10,18]$. With the formation and growth of DRXed grains, the new grains on the interface gradually grow up into the adjacent deformation regions, resulting in the migration of interfacial grain boundaries and the gradual elimination of the bonding interface.

\subsection{Evolution of Interfacial Microstructures and Oxides with Different Holding Time}

In order to further promote bonding quality, post-heating treatment at $400{ }^{\circ} \mathrm{C}$ was performed on the compressed specimens $\left(350^{\circ} \mathrm{C}, \varepsilon=0.6\right)$. To better understand the effect of post-heating treatment and thermodynamic behavior on the bonding interface, heat treatments with different holding times $(1 \mathrm{~h}, 2 \mathrm{~h}, 4 \mathrm{~h}, 8 \mathrm{~h}$ and $12 \mathrm{~h}$ ) were conducted at a certain temperature. Then, the interfacial microstructure and grain size distributions around the bonding interface were examined (Figure 3).
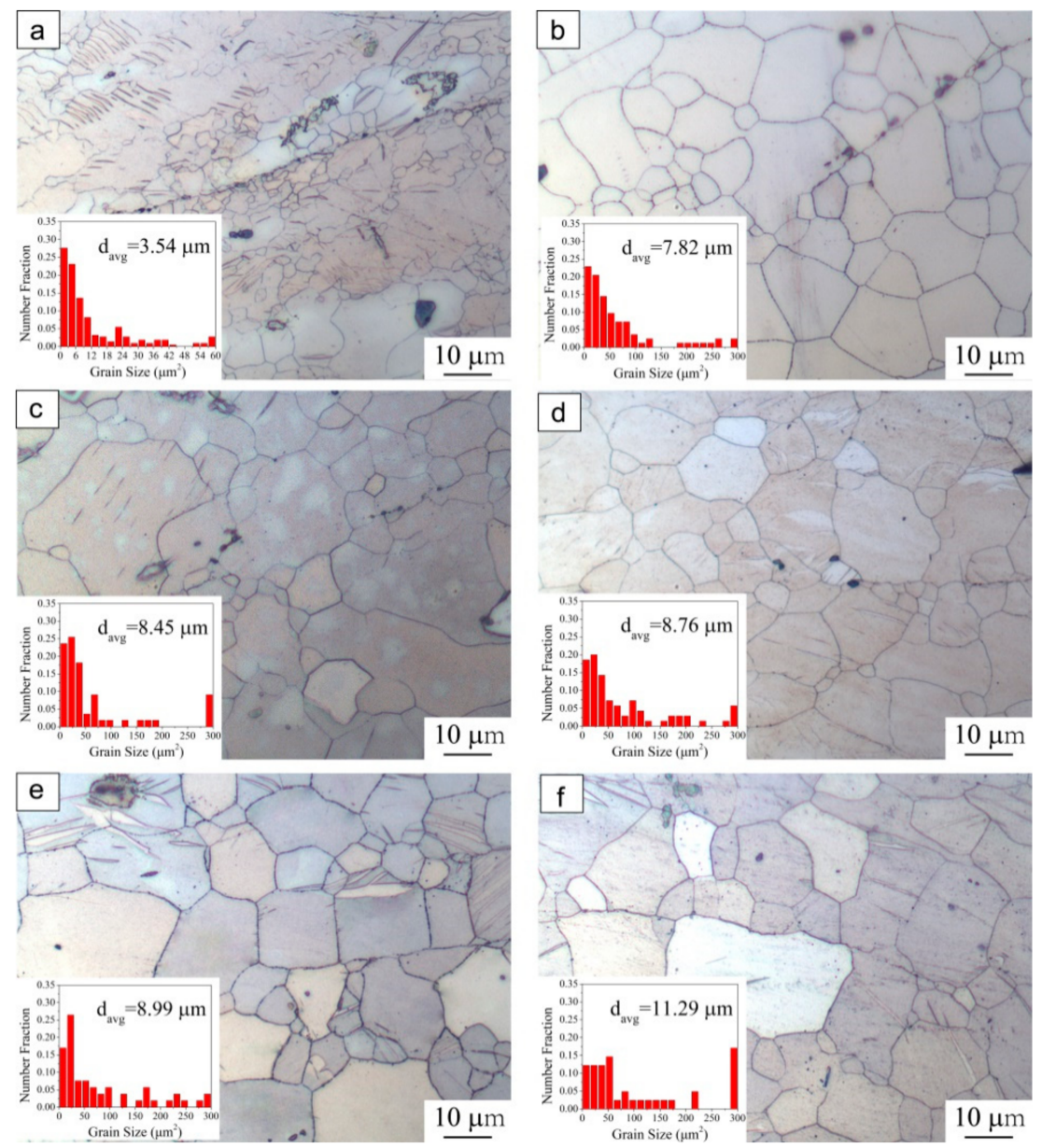

Figure 3. Grain size distributions of compressed specimens $\left(350^{\circ} \mathrm{C}, \varepsilon=0.6\right)$, followed by post-heating treatment at $400{ }^{\circ} \mathrm{C}$ with different holding time: (a) without holding, (b) $1 \mathrm{~h}$, (c) $2 \mathrm{~h}$, (d) $4 \mathrm{~h}$, (e) $8 \mathrm{~h}$, (f) $12 \mathrm{~h}$.

Since no stress was applied during the heat treatment, the axial deformation ratio of post-heated specimens remained the same as the compressed specimens $(\varepsilon=0.6)$. For the as-compressed specimen without heat treatment, grain boundary bonding can be observed and fine DRXed grains were distributed around the bonding interface, as shown in Figure 3a. It can be obviously noted that these fine DRXed grains coarsened after 
holding for $1 \mathrm{~h}$, and the initial bonding interface was close to being completely eliminated (Figure $3 b$ ). In addition, it can be seen that at the initial stage of heating treatment, the grain boundaries along the bonding interface were relatively straight. As the holding time increased to $2 \mathrm{~h}$ and then $4 \mathrm{~h}$ (Figure 3c,d), these grain boundaries became serrated due to the grain boundary evolution, while grain size was not increased significantly. In addition, the bonding interface was gradually eliminated with the evolution of the grains. With increasing treating time, the GB migration ratio further increased. After holding for $8 \mathrm{~h}$ (Figure $3 \mathrm{e}$ ), the grains grew slightly during the heat-treatment process and the bonding interface completely disappeared. This phenomenon implies that during the heat treatment process grain growth could be the driving force for GB migration. With increasing treatment time $(1 \mathrm{~h}-8 \mathrm{~h})$, the grain boundary migration ratio increases and the bonding interface can hardly be observed. On the other hand, this process has some similarities with diffusion bonding, in which the temperature and contact pressure are maintained between the solids for a period of time in order for the atoms to diffuse across the bonding interface [21].

It is quite easy to understand that heat treatment will enhance the bonding quality of as-compressed specimens. However, it was noted that as the holding time further increased to $12 \mathrm{~h}$ (Figure $3 \mathrm{f}$ ), the number of coarse grains increased and the area fraction of fine grain obviously decreased. The bonding area exhibited a coarse and uniform microstructure with increased average grain size of $11.29 \mu \mathrm{m}$, compared with previous sizes ranging from 7.82 8.99 $\mu \mathrm{m}$. This observation is consistent with findings on the grain growth behavior of AZ31 magnesium alloy [22]. The present results indicate that the elongated holding time induced a large amount of coarse grain, which might not be beneficial for the mechanical properties of the bonding parts.

Detailed microstructure observation and elemental characterization were conducted in order to further examine the interfacial characteristics of the as-compressed specimen bonded at $350{ }^{\circ} \mathrm{C}$ under a strain of 0.6, as shown in Figure 4. For the as-compressed specimen, it can be observed that the broken oxide particles scatter around the interface (Figure 4a). In addition, there are two featured contact zones in the bonding interface: one with the fresh metal on both sides, the other with the broken oxide particles between the metal surfaces. According to Figure $4 \mathrm{~b}$, the interfacial oxides were composed of $\mathrm{Mg}, \mathrm{O}$, $\mathrm{Al}, \mathrm{Mn}, \mathrm{Zn}$; the element distribution shows a noticeable change with distance from the bonding interface. The marked points 1 and 4,5 are located on the interface, and points 2 and 3 are away from the bonding interface. In comparison with oxygen element content at different pointed locations, it is found that the fraction of elemental oxygen at the marked points decreased with the distance from the interface. These results indicate that diffusion occurred. Previous research has reported similar behavior observed in the material bonding process $[13,23]$. In this study, the interfacial oxides are considered to be the oxygen source which created an oxygen potential between the interface and the base material. In the initial stage, the abundant interfacial oxides provide sufficient oxygen ions diffusing toward the base material. In addition, the high density of defects in the as-compressed specimens, such as dislocations generated by hot compression deformation, may provide channels for oxygen diffusion [24]. These interfacial oxides possibly impeded the bonding of the interface. Therefore, it was confirmed that the post-heating treatments were necessary in order to promote the interface bonding quality of the as-compressed specimens.

Figure $4 \mathrm{c}-\mathrm{f}$ show the SEM images of the evolution of microstructure and interfacial oxides of specimens bonded at $350{ }^{\circ} \mathrm{C}$ with a strain of 0.6 and then heat treated for different times. After holding for $1 \mathrm{~h}$ (Figure $4 \mathrm{c}$ ), the distributed interfacial oxides became less dense. The evolution of the interfacial oxides can be explained by considering the thermodynamics of the matrix and interfacial oxides. The oxide particles scattered via diffusion from the interface to the internal materials. It has been proved that GB can be the channel for oxide particle diffusion $[25,26]$. Furthermore, prior research has reported that such diffusion is driven by differences in chemical potential arising from changes in interface curvature $[27,28]$. This mechanism can explain the diffusion phenomenon in the bonding area. 

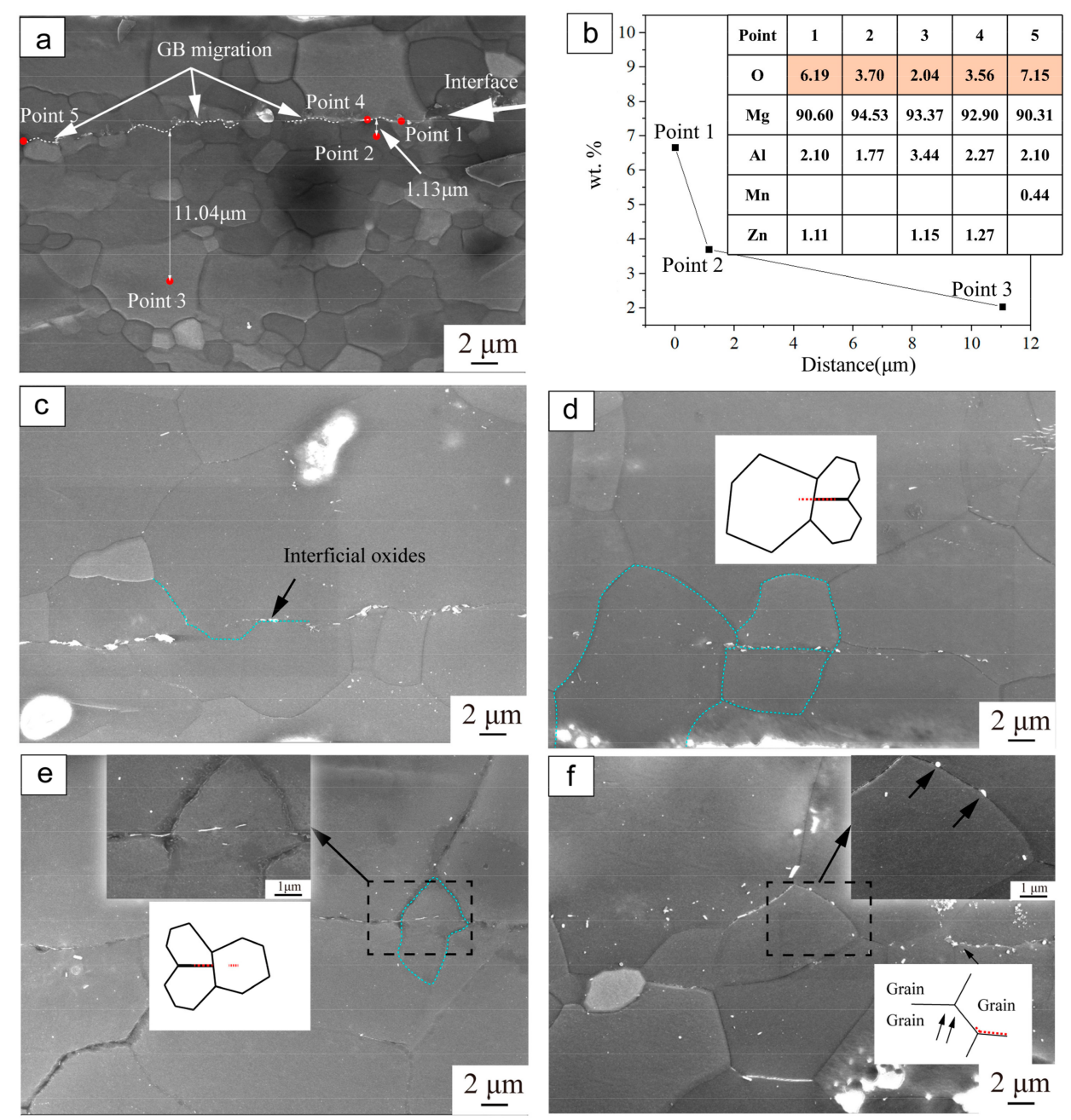

Figure 4. SEM images and EDS results of the interfacial oxides evolved with different holding times: (a) As-compressed under a strain of 0.6, without holding; (b) EDS results of elemental characterization corresponding to the points in Figure 4a; (c-f) Post-holding treated for $1 \mathrm{~h}, 2 \mathrm{~h}, 8 \mathrm{~h}$ and $12 \mathrm{~h}$, respectively.

Additionally, it can be observed that with the evolution of DRX, the new grains on the interface gradually grow up into the adjacent deformation regions, causing the GB to migrate to the opposite sides (Figure 4c). The migration of recrystallized GB is considered to be induced by grain growth, especially occurring at the starting period of heat-treatment. In addition, it can be observed that small oxide particles are dispersed inside the grains. It is considered that in the region rich in small oxide particles, dislocations can be strongly pinned by these oxide particles and accumulate around these sites, resulting in a highlystrained deformation zone [6]. As a result, the fine oxide particles band was kinked by the grain growth, and moved along with GB migration. As the holding time increased (Figure $4 \mathrm{~d}, \mathrm{e}$ ), it was observed that the large GB began to cross the bonding interface and the amount of interfacial oxides further decreased. After holding for $12 \mathrm{~h}$ (Figure $4 \mathrm{f}$ ), the interfacial oxides nearly disappeared, with only a few small particles dispersed away from the bonding interface. Different methods could be proposed for the oxide elimination process, and further research is needed on this topic. Usually, the oxides migrate into base material via GB. Meanwhile, the GB and dislocations could be the channels for atomic transport $[24,29]$, and the elemental oxygen could diffuse with the driving force of the chemical gradient between the oxides and the base material. 


\subsection{Tensile Properties}

Tensile tests were carried out at the speed of $3 \mathrm{~mm} / \mathrm{min}$ parallel to the compression direction. Figure 5 shows the UTS of the bonded specimens and base materials undergoing the same heat treatment. The two curves exhibited almost the same trend. In other words, the bonded specimens showed similar tensile behavior to the base material, while the UTS of the bonded specimens were slightly lower than that of the base material. It can be seen that when the holding time increased from $1 \mathrm{~h}$ to $4 \mathrm{~h}$, the UTS of the bonded specimens did not show obvious improvement. As the holding time increased from $4 \mathrm{~h}$ to $8 \mathrm{~h}$, the UTS of the bonding specimens reached $164.7 \mathrm{MPa}$, improving about $9 \%$ compared with that of holding for $1 \mathrm{~h}$. It is interesting to note that when the holding time was further increased to $12 \mathrm{~h}$, the UTS of base materials and bonded specimens declined evidently. As the holding time increased, the bonding strength improved as a result of GB migration across the initial bonding interface. However, the UTS of specimens holding for $12 \mathrm{~h}$ decreased owing to the large number of coarse grains, as observed in Figure $3 \mathrm{f}$.

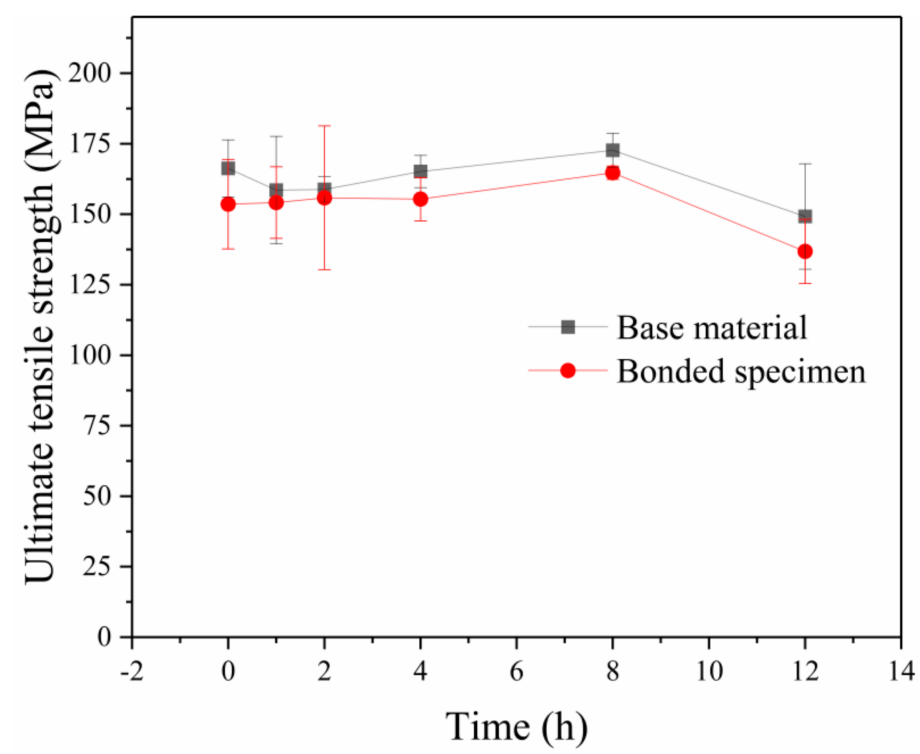

Figure 5. Ultimate tensile strength of the specimens with different holding times for base material and bonded specimens.

Figure 6 depicts the SEM fracture morphologies of the bonded specimens under different holding times. Differences in fracture morphology between specimens with and without post-heating treatment could be observed. As can be seen in Figure 6a, the ascompressed specimen showed the quasi-cleavage fracture with a small amount of dimples and tear ridges, which indicated poor plasticity. In contrast, after holding for $2 \mathrm{~h}$ (Figure $6 \mathrm{~b}$ ), the fracture surface showed a large number of shallow dimples due to improvement in the bonding ratio, indicating the occurrence of a mixed ductile mode of fracture. With increasing time of heat-treatment to $8 \mathrm{~h}$ (Figure 6c), the dimples became deeper and the number of dimples increased, which indicates better plasticity due to the high bonding ratio and migration of the GB along the bonding interface. The characterized morphology indicates that the fracture mechanism of the interface is ductile failure mode [30]. After holding for $12 \mathrm{~h}$ (Figure 6d), the dimples became larger and looser compared to after holding for $8 \mathrm{~h}$, due to the increasing grain size. Apparently, the fracture surface morphologies indicate the features of ductile fracture and the numerous dimples with different sizes distributed on fracture surfaces after heat-treatment process. The SEM results for the fracture surface are in good agreement with the results on tensile properties. 

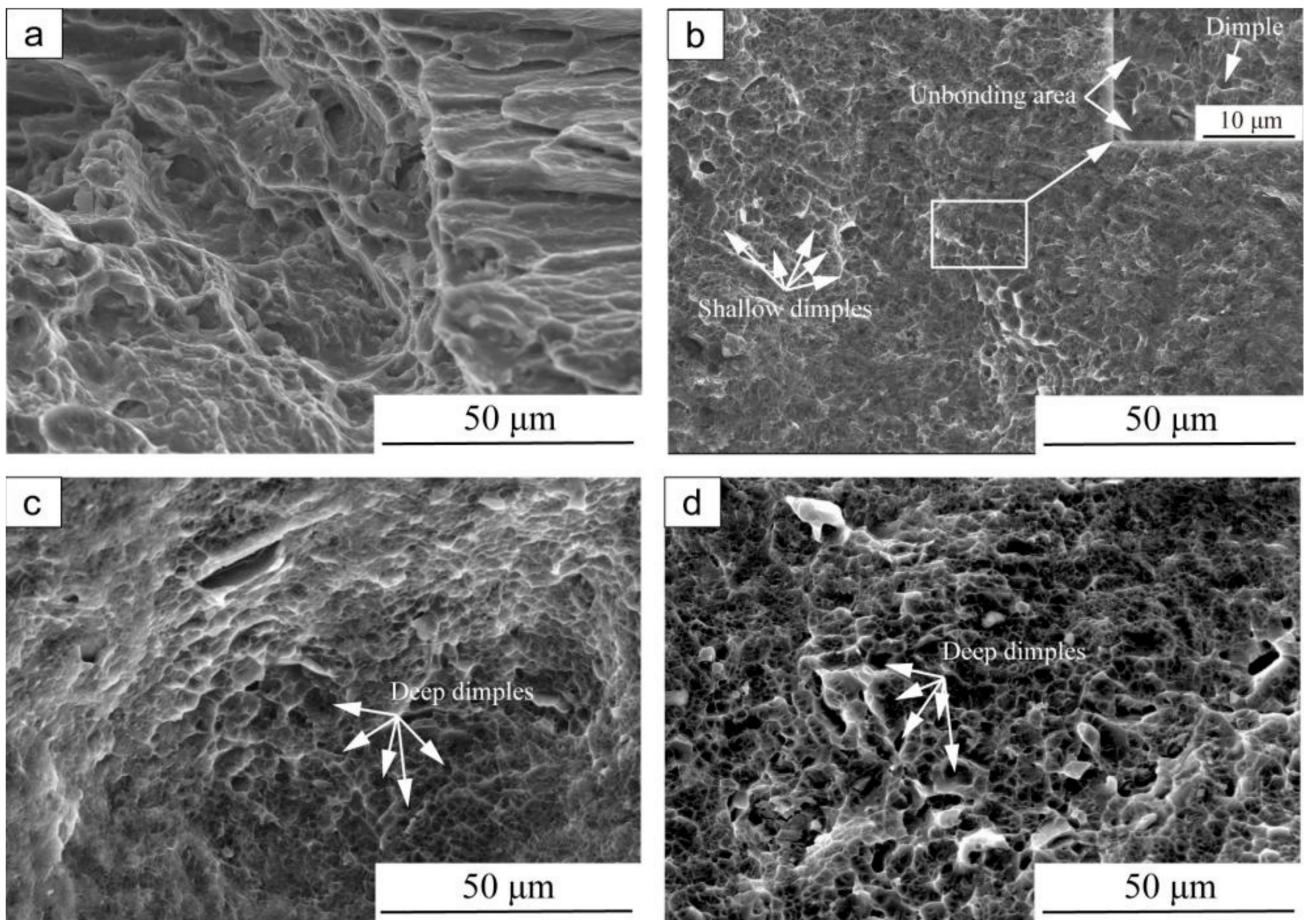

Figure 6. SEM fracture surface morphologies of compressed specimens $\left(350{ }^{\circ} \mathrm{C}, \varepsilon=0.6\right)$, followed by post-heating treatment at $400{ }^{\circ} \mathrm{C}$ with different holding time: (a) without holding, (b) $2 \mathrm{~h}$, (c) $8 \mathrm{~h}$, (d) $12 \mathrm{~h}$.

\subsection{Bonding Mechanisms}

In summary, the interface bonding mechanism during hot compression and postheating treatment of AZ31 magnesium alloy is schematically illustrated in Figure 7. As shown in Figure 7a, the interfaces are completely unbound prior to the joining process and oxides have formed along the interfaces upon heating. Once hot compression begins, the two metallic surfaces come into contact and the nucleation of DRXed grains initially occurs at the bonding interface (Figure $7 \mathrm{~b}$ ). As the strain increases, the DRXed grains gradually spread and continue to evolve. Driven by the stored energy difference correlated with the dislocation density near the grain boundaries, strain-induced GB migration occurs, resulting in the serration of the bonding line. Meanwhile, this process can produce large deformation, thus effectively breaking the possible surface oxide that is a barrier to the formation of a metal-metal bond. Consequently, the exposed fresh surfaces are then joined under the compressive force perpendicular to the interface, where the initial bonding interface turns into a GB migration area. This newly formed bonding area is named the GB bonding area. The bonding interface contains interspersed fine grains (Figure 7c). During the post-heating treatment, GB migration is driven by the growth of recrystallized grains. At this stage, there is no significant gradient of driving force for GB migration. With further increase in the holding time, the recrystallized grain boundaries migrate towards both sides of the bonding line (Figure $7 \mathrm{~d}$ ). As a result, the oxides migrate into the base material through GB and the initial bonding line gradually disappears (Figure 7e). After holding for enough time, the newly recrystallized grains spread across the bonding interface and a sound bonding finally forms with only a few dispersed small oxide particles (Figure 7f). 


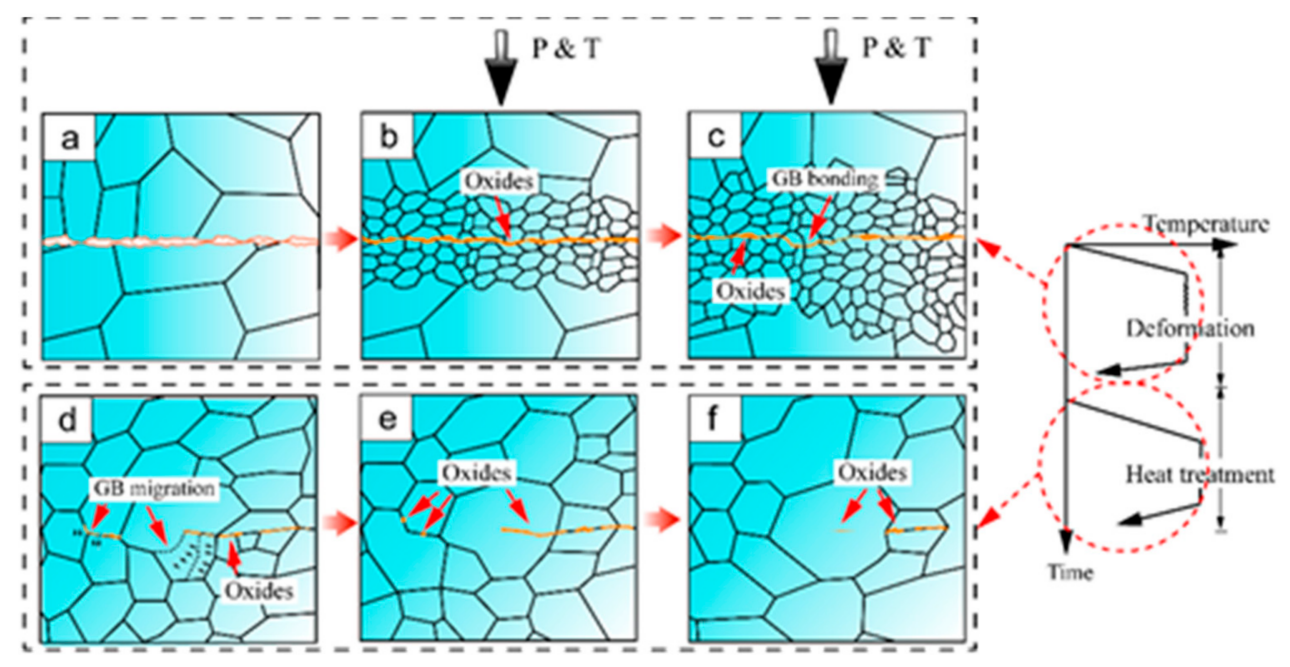

Figure 7. Schematic illustration of the interface bonding mechanism.

\section{Conclusions}

Interfacial microstructural evolution during the interface bonding process of AZ31 magnesium alloy was investigated and the bonding mechanisms were analyzed. The main conclusions are as follows:

For engineering applications, it is possible to achieve a sound bond quality for AZ31 magnesium alloy via plastic deformation followed by heat treatment. The bonding quality is dependent on the interfacial microstructure induced by the bonding parameters.

The main mechanisms of bonding interface elimination are the evolution of DRXed grains and GB migration, dependent on temperature, strain level and holding time.

Interfacial microstructure analysis indicates that the bonding process is closely related to the development of fine DRXed grains under high strain levels (0.4-0.6). The optimal heat treatment holding time was $8 \mathrm{~h}$ and the interfacial bonding strength reached $164.7 \mathrm{MPa}$, an enhancement of about 9\% compared with that of the specimens with a holding time of $1 \mathrm{~h}$.

During deformation, strain-induced GB migration plays an important role in the bonding process. At the post-heating treatment stage, GB migration was mainly driven by the growth of grains, and oxide particles scattered via diffusion from the interface to the base material.

Author Contributions: Conceptualization, L.R. and Z.C.; methodology, L.R.; software, B.L.; investigation, B.L., Y.Q.; resources, L.Q.; writing-original draft preparation, B.L. and L.R.; writing-review and editing, L.R., Z.C. and S.G.; funding acquisition, L.R. All authors have read and agreed to the published version of the manuscript.

Funding: This research was funded by National Natural Science Foundation of China, grant number 51704262 .

Institutional Review Board Statement: Not applicable.

Informed Consent Statement: Not applicable.

Data Availability Statement: There are any data need to be reported.

Conflicts of Interest: The authors declare no conflict of interest.

\section{References}

1. Song, J.F.; She, J.; Chen, D.L.; Pan, F.S. Latest research advances on magnesium and magnesium alloys worldwide. J. Magnes. Alloys 2020, 8, 1-41. [CrossRef]

2. Ramalingam, V.V.; Ramasamy, P.; Kovukkal, M.D.; Myilsamy, G. Research and development in magnesium alloys for industrial and biomedical applications: A review. Met. Mater. Int. 2020, 26, 409-430. [CrossRef]

3. Ali, Y.; Qiu, D.; Biang, B.; Pan, F.S.; Zhang, M.X. Current research progress in grain refinement of cast magnesium alloys: A review article. J. Alloys Compd. 2015, 619, 639-651. [CrossRef] 
4. Chaudry, U.M.; Hamad, K.; Kim, J.G. On the ductility of magnesium based materials: A mini review. J. Alloys Compd. 2019, 792, 652-664. [CrossRef]

5. Zhang, C.; Li, M.Q.; Li, H. Diffusion behavior at void tip and its contributions to void shrinkage during solid-state bonding. J. Mater. Sci. Technol. 2018, 34, 1449-1454. [CrossRef]

6. Liu, H.; Ushioda, K.; Fujii, H. Elucidation of interface joining mechanism during friction stir welding through $\mathrm{Cu} / \mathrm{Cu}-10 \mathrm{Zn}$ interfacial observations. Acta Mater. 2019, 166, 324-334. [CrossRef]

7. Ruppert, A.; Schunk, C.; Hausmann, D.; Höppel, H.W.; Göken, M. Global and local strain rate sensitivity of bimodal Al-laminates produced by accumulative roll bonding. Acta Mater. 2016, 103, 643-650. [CrossRef]

8. Zhang, C.; Li, H.; Li, M.Q. Detailed evolution mechanism of interfacial void morphology in diffusion bonding. J. Mater. Sci. 2016, 32, 259-264. [CrossRef]

9. Zhang, J.Y.; Xu, B.; Tariq, N.H.; Sun, M.Y.; Li, D.Z.; Li, Y.Y. Effect of strain rate on plastic deformation bonding behavior of Ni-based superalloys. J. Mater. Sci. 2020, 40, 54-63. [CrossRef]

10. Zhang, H.; Li, J.L.; Ma, P.Y.; Xiong, J.T.; Zhang, F.S. Study on microstructure and impact toughness of TC4 titanium alloy diffusion bonding joint. Vacuum 2018, 152, 272-277. [CrossRef]

11. Zhang, C.; Li, H.; Li, M.Q. Formation mechanisms of high quality diffusion bonded martensitic stainless steel joints. Sci. Technol. Weld. Join. 2015, 20, 115-122. [CrossRef]

12. Zhang, J.Y.; Sun, M.Y.; Xu, B.; Hu, X.; Liu, S.; Xie, B.J.; Li, D.Z. Evolution of the interfacial microstructure during the plastic deformation bonding of copper. Mater. Sci. Eng. A 2019, 746, 1-10. [CrossRef]

13. Xie, B.J.; Sun, M.Y.; Xu, B.; Wang, C.Y.; Li, D.Z.; Li, Y.Y. Dissolution and evolution of interfacial oxides improving the mechanical properties of solid state bonding joints. Mater. Des. 2018, 157, 437-446. [CrossRef]

14. Gao, X.J.; Jiang, Z.Y.; Wei, D.B.; Jiao, S.H.; Chen, D.F.; Xu, J.Z.; Zhang, X.M.; Gong, D.Y. Effects of temperature and strain rate on microstructure and mechanical properties of high chromium cast iron/low carbon steel bimetal prepared by hot diffusioncompression bonding. Mater. Des. 2014, 63, 650-657. [CrossRef]

15. Huang, K.; Logé, R.E. A review of dynamic recrystallization phenomena in metallic materials. Mater. Des. 2016, 111, 548-574. [CrossRef]

16. Xu, X.; Ma, X.W.; Yu, S.B.; Zhao, G.Q.; Wang, Y.X.; Chen, X.X. Bonding mechanism and mechanical properties of $2196 \mathrm{Al}-\mathrm{Cu}-\mathrm{Li}$ alloy joined by hot compression deformation. Mater. Charact. 2020, 167, 110486. [CrossRef]

17. Zhang, J.Y.; Xu, B.; Tariq, N.U.H. Microstructure evolutions and interfacial bonding behavior of Ni-based superalloys during solid state plastic deformation bonding. J. Mater. Sci. Technol. 2020, 46, 1-11. [CrossRef]

18. Mori, K.; Bay, N.; Fratini, L.; Micari, F.; Tekkaya, A.E. Joining by plastic deformation. CIRP Ann. 2013, 62, 673-694. [CrossRef]

19. Belyakov, A.; Sakai, T.; Miura, H.; Kaibyshev, R.; Tsuzaki, K. Continuous recrystallization in austenitic stainless steel after large strain deformation. Acta Mater. 2002, 50, 1547-1557. [CrossRef]

20. Wusatowska-Sarnek, A.M.; Miura, H.; Sakai, T. Nucleation and microtexture development under dynamic recrystallization of copper. Mater. Sci. Eng. A 2002, 323, 177-186. [CrossRef]

21. Srikanth, V.; Laik, A.; Dey, G.K. Joining of stainless steel $304 \mathrm{~L}$ with Zircaloy-4 by diffusion bonding technique using Ni and Ti interlayers. Mater. Des. 2017, 126, 141-154. [CrossRef]

22. Zhao, L.Y.; Xin, Y.C.; Jin, Z.Y.; Wang, J.; Feng, B.; Liu, Q. Thermal stability of different texture components in extruded Mg-3Al-1Zn alloy. J. Magnes. Alloys 2019, 7, 577-583. [CrossRef]

23. Mao, W.C.; Sloof, W.G. Relation between oxygen activity gradient in the internal oxidation zone of Mn alloyed steel and the composition of oxide precipitates. Scr. Mater. 2017, 135, 29-32. [CrossRef]

24. Divinski, S.V.; Reglitz, G.; Rösner, H.; Estrin, Y.; Wilde, G. Ultra-fast diffusion channels in pure Ni severely deformed by equal-channel angular pressing. Acta Mater. 2011, 59, 1974-1985. [CrossRef]

25. Yeh, S.Y.; Chen, C.C.; Lan, C.W. Adaptive phase field modeling of grain boundary diffusion. J. Cryst. Growth 2011, 318, 46-50. [CrossRef]

26. Kim, T.H.; Lee, S.R.; Yun, S.J.; Lim, S.H.; Kim, H.J.; Lee, M.W.; Jang, T.S. Anisotropic diffusion mechanism in grain boundary diffusion processed Nd-Fe-B sintered magnet. Acta Mater. 2016, 112, 59-66. [CrossRef]

27. Ma, R.F.; Li, M.Q.; Li, H.; Yu, W.X. Modeling of void closure in diffusion bonding process based on dynamic conditions. Sci. China Technol. Sci. 2012, 55, 2420-2431. [CrossRef]

28. Hill, A.; Wallach, E.R. Modelling solid-state diffusion bonding. Acta Metall. 1989, 37, 2425-2437. [CrossRef]

29. Wilde, G.; Ribbe, J.; Reglitz, G.; Wegner, M.; Rösner, H.; Estrin, Y.; Zehetbauer, M.; Setman, D.; Divinski, S. Plasticity and grain boundary diffusion at small grain sizes. Adv. Eng. Mater. 2010, 12, 758-764. [CrossRef]

30. Deng, Y.H.; Guan, Q.; Wu, B.; Wang, X.W.; Tao, J. Study on rigid restraint thermal self-compressing bonding-A new solid state bonding method. Mater. Lett. 2014, 129, 43-45. [CrossRef] 